\title{
Bir Dijital Kültür Örneği Olarak Katılımcı Sözlükler ve Türkiye'deki Görünümleri
}

Rıdvan Yücel ${ }^{1}$

Akdeniz Üniversitesi

ridvanyucel@akdeniz.edu.tr

ORCID: 0000-0001-8976-7213

M. Bilal Arık ${ }^{2}$

Aydın Adnan Menderes Üniversitesi

mbarik@adu.edu.tr

ORCID: 0000-0002-4020-0555

\section{ÖZET}

Ses, yazı, fotoğraf, hareketli görüntü ve grafiklerin rakamsal değerlere, kodlara dönüştürülerek kullanıcılar arasında paylaşılması şeklinde tanımlanabilecek dijitalleşme, iletişim ve kültürü derinden etkilemiştir. internetin devreye girmesi, özellikle de Web 2.0. teknolojisinin kullanımı ile birlikte daha katılımcı ve etkileşimli bir iletişim ortamı doğmuştur. Dijital katılıma sözlükler bu teknolojik ilerlemelerin üzerine bina edilmiş ve dijitalleşmenin bütün özelliklerini taşıyan platformlar olarak ortaya çıkmışlardır. Dijital katılımcı sözlüklerde kullanıcılar kendi içeriklerini hazırlayabilmekte, var olanları dönüştürebilmekte veya kopyalayarak yeniden dolaşıma sokabilmektedir. Betimsel tarihsel inceleme olarak tasarlanan bu makalede bir dijital kültür ürünü olan katılımcı sözlüklerin işleyiş biçimlerine bakılmıştır. Dijital kültürde, katılımcı sözlüklerin konumlarının ele alındığı bu bölümün ardından, sözlüklerin Türkiye'deki tarihsel gelişimi ana hatlarıyla incelenmiştir. Türkiye'de 1999 yılında Ekşi Sözlük ile başlayan akım pek çok farklı sözlüğün katılımıyla zaman içerisinde genişlemiştir. Ekşi sözlük zamanla ciddi bir popülariteye ulaşmış aynı zamanda içerikleri nedeniyle de ağır eleştirilere maruz kalımıştır. Çalışmanın sonunda dijital sözlüklerin bir yandan daha sivil, eğlenceli ve herkesin katılımına açık bir atmosfer sunarken, diğer yandan ciddi sorunları içerdiği sonuçlarına ulaşılmıştır.

Anahtar Kelimeler: Dijital Kültür, Dijitalleşme, Katılımcı Sözlükler, Ekşi Sözlük, Katılımcı.

\footnotetext{
1 Öğretim Görevlisi Doktor. Akdeniz Üniversitesi.

2 Profesör. Aydın Adnan Menderes Üniversitesi.
} 


\title{
Collaborative Dictionaries
}

\section{as an Example of Digital Culture and Their Appearances in Turkey}

Application Date: 04.12 .2020

Accepted Date: 11.12 .2020

Publishing Date: 30.12 .2020

\author{
Rıdvan Yücel ${ }^{3}$ \\ Akdeniz University \\ ridvanyucel@akdeniz.edu.tr \\ iD ORCID: 0000-0001-8976-7213 \\ M. Bilal Arık \\ Aydın Adnan Menderes University \\ mbarik@adu.edu.tr \\ (iD) ORCID: 0000-0002-4020-0555
}

\begin{abstract}
Digitalization, which can be defined as the conversation of sound, text, photographs, moving images and graphics into numerical values and codes and sharing them among users, has deeply affected communication and culture. The introduction of the internet, especially along with the usage of Web 2.0, more collaborative and interactive communication environment has emerged. Digital collaborative dictionaries are built on these technological progresses and have ensued as platforms which have all characteristics of digitalization. In digital collaborative dictionaries, users can prepare their own content, transform existing ones or put them back into circulation by copying. In this article, which was designed as a descriptive historical research, the action of collaborative dictionaries as a digital culture product were discussed. Following this section discussed the positions of collaborative dictionaries in digital culture, historical development of dictionaries in Turkey was outlined. In 1999 in Turkey the trend started with Ekşi Sözlük together with collaboration of many different dictionaries has expanded over the time. Ekşi Sözlük has reached a serious popularity over time, and at the same time it has been heavily criticized for its contents. At the end of the study, it was concluded that digital dictionaries, on the one hand, offer a more civic, fun and open atmosphere for every participant, on the other hand they contain serious problems.
\end{abstract}

Keywords: Digital Culture, Digitalization, Collaborative Dictionaries, Ekşi Sözlük, Participation

\footnotetext{
3 Lecturer Ph.D.. Akdeniz University.

${ }^{4}$ Professor. Aydın Adnan Menderes University.
} 


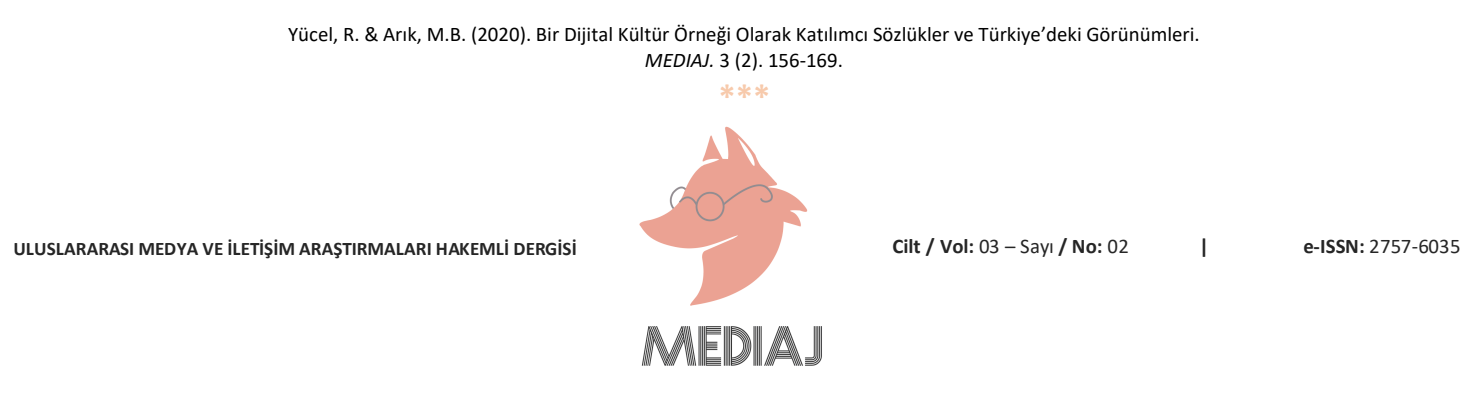

\section{Giriş}

Teknolojinin gelişmesiyle birlikte iletişim araçlarında ve iletişim biçimlerinde büyük değişimler yaşanmıştır. Illetişim aracının kendisinde yaşanan değişimler, salt iletişim pratiklerini değiştirmekle kalmamakta; toplumsal örgütlenmelerden bilginin oluşum ve yayılma pratiklerine de yansımaları olmaktadır. Bu çerçevede en önemli örneklerden birisi olarak katılımcı dijital sözlükler karşımıza çıkmaktadır. Bilgisayar ve internet birlikteliğinin en tipik örneklerinden olan dijital sözlükler dijital iletişimin hem olumlu hem de olumsuz özelliklerini taşımaktadır. Örnek olarak hem doğru bilgi hem de yanlış bilgi çok hızı yayılabilmekte, insanların kendilerini ifade etme imkanları genişlerken nefret söylemi ve ayrımcılık da paralel olarak artabilmektedir. Bu noktada dijitalleşme olgusunun dinamiklerine odaklanarak yeni iletişim alanlarının getirdiği imkanları ve riskleri daha iyi anlamak gerekmektedir. İletişim pratiği açısından dijitalleşme kavramını ele alacak olursak dijitalleşmeyi ses, yazı, fotoğraf, hareketli görüntü ve grafiklerin rakamsal değerlere, kodlara dönüştürülerek kullanıcılar arasında paylaşılması şeklinde özetlemek mümkündür. Kullanıcılar sahip oldukları bilgisayar temelli iletişim aygıtlarıyla bağlantılar üzerinden bir araya gelmekte ve bir ağ oluşturmaktadır. Bu ağ üzerinden herkes her an her türlü bilgiye ulaşabilme imkanına kavuşmakta, akıllı cihazlar sayesinden herkes içerik üretebilir konumda bulunmaktadır. Bu anlamda dijitalleşme insanları potansiyel olarak içeriğe ulaşma ve üretme noktasında eşitlemiş görünmektedir.

Dijitalleşme internetin bant genişliğinin artması ve kullanıcı türevli içeriklerin üretiminin yaygınlaşmasıyla insanların hayatında önemli bir yer edinmiştir. WEB 2.0. olarak da bilinen bu teknolojik yenilik bilgi işlem, sayısallaşma, fiber optik teknolojisindeki ilerleme, veri sıkıştırma gibi ilerlemeleri ifade etmektedir. Dijital katılımcı sözlükler bu teknolojik ilerlemelerin üzerine bina edilmiş ve dijitalleşmenin bütün faziletlerini ve hastalıklarını taşıyan platformlar olarak ortaya çıkmışlardır.

Betimsel tarihsel inceleme olarak tasarladığımız bu makalede bir dijital kültür ürünü olan katılımcı sözlüklerin arka planı, çalışma prensipleri incelenecek ve Türkiye'deki kısa tarihlerine yer verilerek, başta bu alanın en etkili platformu olan Ekşi Sözlük olmak üzere katılımcı sözlüklere yönelik eleştirilere yer verilecektir. Son yılların en dinamik ortamlarından biri olan katılımcı sözlüklere ilişkin, kısıtlı sayıdaki akademik incelemelere katkı sağlamayı amaçlayan bu çalışma, özellikle dijital kültür ve sözlükler ilişkisini ortaya koyması açısından önem taşımaktadır.

\section{Dijital Kültür ve Özellikleri}

Dijitalleşme pek çok seviyede teknik ilerlemenin tabana yenilik olarak yayılmasının bir sonucudur. Dijitalleşme ile birlikte telekomünikasyon, veri iletimi ve kitle iletişimini tek ortamda birleşmiştir. Yöndeşme olarak adlandırılan bu sürecin sonunda medya yeni medyaya dönüşmüş ve multimedya olarak adlandırılır hale gelmiştir.

Dijitalleşme, tüm sinyallerin bit adı verilen ve sadece sıfır ve birlerden oluşan ufak parçalara bölünmesi demektir. Mikro-elektronik dalındaki ilerlemelerin yardımıyla bu bitler hızla ve karışma olmaksızın taşınabilir ve bağlanabilirler. En iyi sonuçları ileticiyle alıcı arasındaki tüm 


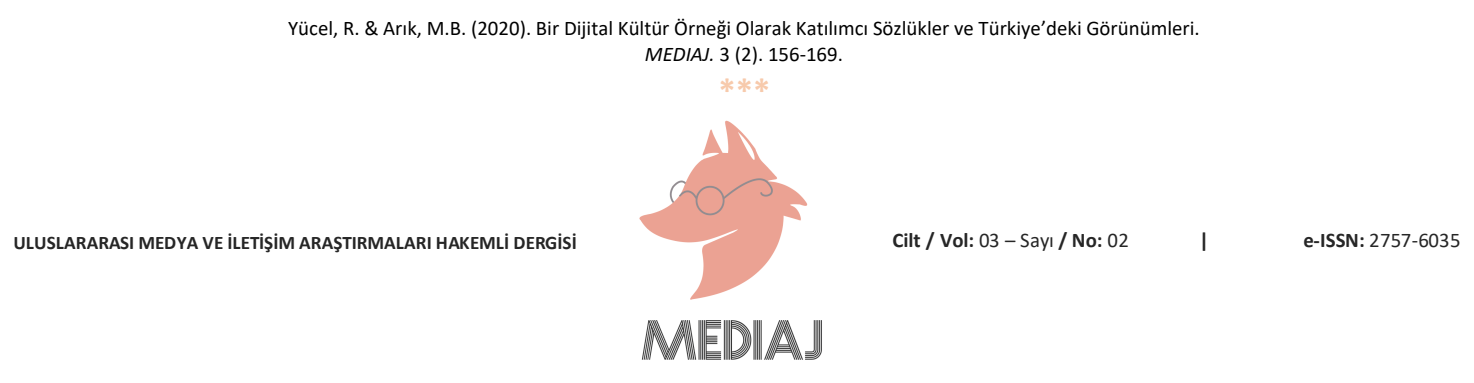

bağlantının dijital sinyallerden oluştuğu durumlarda alınır. Veriler kolaylıkla işlenir, metinler kelime işlem için hazırlanır ve sesler ve görüntüler daha kaliteli hale gelir. Yine de bu teknik üstünlük tüm dolayımlanmış iletişimde görülen hızlı dijitalleşmenin tek nedeni değildir. Bu daha çok tamamen dijitalleşmiş veri iletişiminde görülen inanılmaz artışı tamamen yöndeşmiş bir altyapı içerisinde özümleme ihtiyacından ortaya çıkmıştır. Dijitalleşme ile veri iletimi ve bilgisayar teknolojisi tüm iletişim altyapılarındaki baskın unsurlar haline gelmiştir (Van Dijk, 2018, s. 7879).

Van Dijk, tüm iletişim araçlarının tamamen dijitalleşmesi (dijital kodun genel kullanımı) ve kablo veya havadan tüm bağlantıları kullanan geniş bant iletimi sayesinde dijital entegrasyon sürecinin gerçekleştiğini ileri sürmektedir (Van Dijk, 2018, s. 21). Dijk, ortam teorisi kavramsallaştırmasıyla tarihsel açıdan iletişim araçları ve teknolojilerin aynı zamanda tanımlayıcı olduğunu da öne sürmektir. O'na göre, iletişim araçları, kullanıcıların sosyal çevreleri içerisinde kullanıcılar üzerinde etki sahibi olan nesnel özelliklere sahiptir. Araçların iletişim kapasiteleri de buna bir örnek oluşturmaktadır. Buradaki temel sav, iletişim araçları ve teknolojilerin de birer sosyal çevre oldukları yönündedir. Bu varsayım medya ağları için kesinlikle geçerlidir (Van Dijk, 2018, s. 37).

Dijitalleşme ile birlikte etkileşim son derece artmış, hedef kitle de kaynak gibi mesaj üretebilir hale gelmiştir. Bu arada hedef kitle son derece genişlemiş, sınırlar belirsizleşmiştir. Dijitalleşme aynı zamanda geleneksel iletişim araçları ve kitle arasındaki zaman ve mekân dengesini de parçalayarak eş zamansız bir ortam yaratmıştır.

Dijitalleşmede en önemli dönüm noktası $90^{\prime} \mid ı$ yılların ortasından itibaren internetin devreye girmesi ile yaşanmıştır. İnternet ile birlikte etkileşim hiç olmadığı kadar yoğunlaşmış ve geleneksel iletişim araçlarındaki hedef kitlenin iletişim sürecindeki etkinliği artmıştır.

"Web 1.0 döneminde daha statik bir içeriğe sahip olan internetin kullanıcıları ile etkileşimi sınırlıdır. Burada tıpkı geleneksel medyada olduğu gibi, tek yönlü ve kaynağın baskın olduğu bir iletişim ortamı söz konusudur. Fakat 2000'li yıllarla birlikte Web 2.0 teknolojisi ile birlikte daha etkileşimli, kullanıının kontrol imkanının arttığı, bilgi paylaşımına açık ve sosyal katılıma uygun bir ortam doğmuştur. Bloglar, arama motorları, sözlükler, videolar, fotoğraflar, sosyal ağlar, wikiler devreye girmiş, internet ortamı çeşitlenmiş ve renklenmiştir. Web 2.0 ile birlikte internet bir kitle iletişim aracı olmanın çok daha ötesine geçerek, adeta yeni bir toplumsal ortama dönüşmüştür"(Arık, 2018, s. 76).

Dijitalleşme ile birlikte izleyici ve okurların yerini aktif kullanıcılar almıştır. Kullanıcılar geleneksel kitle iletişim sürecindeki hedef kitleye kıyasla çok daha etkin, müzakereci ve seçicidir. Kullanıcılar iletişim sürecinin hedefi değil hem kaynağı hem de üreticileri haline gelmişler, özellikle de sosyal medya ile birlikte içeriğe yön verir hale gelmişlerdir. Dijitalleşme ile birlikte farklı kitle iletişim araçları önce sayısal televizyonlarda, ardından bilgisayarlarda ve nihayet günümüzde akıllı cep telefonlarında toplanır hale gelmiştir. Yakınsama olarak adlandırılan bu sürecin sonunda en etkin iletişim aracı, adı üzerinde mobil olan telefonlar olmuştur. 


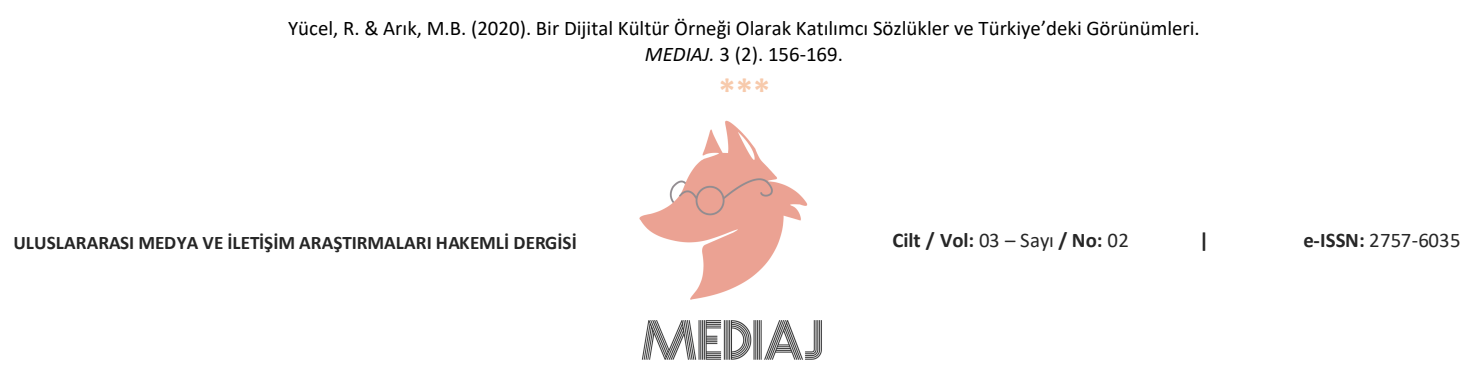

Internette multimedya ortamı olarak adlandırılan metin, görüntü, ses ve videoyu birleştirerek sunan çoklu bir ortam vardır. Böylece internet iletişim bakımından salt bir türe indirgenemeyen eklektik bir dille yapılan iletişim biçimini barındırır. İnternetle katılımcı rol de ortaya çıkmıştır çünkü birinin yarattığı içeriğe anında görüş bildirme ve geri bildirim alma olanağı doğmuştur. Castells'e (2013) göre internetin yaygınlaşması çokluktan çokluğa mesaj gönderme kapasitesini arttırmış, yeni bir tür interaktif iletişimi mümkün kılmıştır. İnteraktif iletişim, kullanıcıların katılımına ve müdahalesine imkan veren bir yapı sunmaktadır (Aydoğan, 2014, s. 22).

Dijital kültürde, internet ve bilgisayar türevli mobil aygıtlar üzerinden gerçekleşen iletişim, kendi zamanının ruhunu yansıtan birtakım yönelimler göstermektedir. İletişim artık sadece anlaşmamızı sağlayacak yöntem olmanın dışına niceliksel niteliklere bürünmüştür. İletişimin sosyal medya fenomeni üzerinde somutlaşması ona verimliliği olan bir nesne gözüyle bakılmasına neden olmaktadır. İletişimin temeli olan mesaj artık bir üründür ve üretilebilir, paylaşılabilir bir nitelikle donatılmıştır. Mesaj üretimi tasarlanabilir ve planlanabilirdir. Üretilen veya hazır hale getirilen mesaj ise diğerleri tarafından paylaşılarak tüketilen ve tüketilirken aynı zamanda başkalarının tüketimi için üretilmiş olan müşterek ve dönüşümlü bir süreç halinde imal edilmekte veya tüketilmektedir. Dijital iletişimin doğası gereği çok hızlı olması ve hızlı akan bir nehre benzemesi nedeniyle, verimliliği yüksek bir mesaj tasarlamanın temeli, onu basit tutmaktır. En fazla beğeni ve paylaşımı yakalamak isteyen mesaj basit, sade ve kısa olmak zorundadır. Basitlik ve sadelik hem mesajı tasarlayan hem de mesajı alacak olan hedef kitle açısından, çift yönlü bir öneme haizdir. Böylelikle iletişim mesajın söz konusu karaktere bürünebilme yeteneğine bağı olarak verimliliği gerçekleştirmiş olmaktadır. Bu anlamda 180 karakterle sınırlanmış bir Twitter'ın bugünün iletişim ortamında revaçta olması teknolojiye göre şekillenen iletişim alışkanlıklarının aktığı mecrayı göstermesi bakımından oldukça manidardır (Göker, 2015, s. 403).

İletişimin dijitalleşmesi kişisel yüz yüze iletişimi de dönüştürmüştür. İnsanlar akıllı cihazları sayesinde, başkalarıyla aynı mekânda olmadan yüz yüze görüşmeler yapabilmekte, bulundukları yerden büyük bir ağın parçası haline gelebilmektedir. Sanal kimliklerle, inşa edilen kişiliklerle, arzu edilen görüntüyü dışarıya yansıtarak yeni bir cemaat ortaya çıkmaktadır. Gerçek kimliğin sınırlarından kurtulan bireyler, aynı mekânda ve tanınıyor olmamanın verdiği güvenle toplumsal normlardan kurtularak ifadede bulunmaktadır. Her an ve her yerde sanal kimliklerle gerçekleşen iletişim, geleneksel iletişim ortamlarının belirleyici iki unsuru olan "zaman ve mekân" kavramlarını bulanıklaştırmaktadır. Ortaya çıkan yeni, hızlı, her zaman ve her yerde olan bireyselkitlesel iletişim biçimini içeriklere yansımaktadır. Dijital sözlükler bağlamında ele alınacak olursa, daha öznel, anlık, duygusal, keyfi ifadelerin dolaşımda olduğu bir iletişim biçimi kamusal alanı doldurmaya başlamıştır. Otorite ve doğruluk ölçüsü yazarların kendileri ve yazarların öznel deneyimlerinden yine kendilerine kalanlardır.

\section{Dijital Kültür ve Katılımcı Sözlükler}

Dijitalleşme iletişim sürecine yeni bir öğe katmamıştır ancak yazı, görüntü, ses gibi iletişim unsurlarının üretilmesi ve yayılması önceki dönemlerle kıyaslanamayacak biçimde artmıştır. Bununla birlikte iletişim unsurlarını hazırlamak ve dolaşıma sokmak medya profesyonellerine has bir ayrıcalık olmaktan çıkmış, bilgisayar becerisi ve bağlantısı olan herkesin yapabileceği iletişim eylemlerine dönüşmüştür. Bu çerçevede gerek iletişim unsurlarının gerekse var olan 


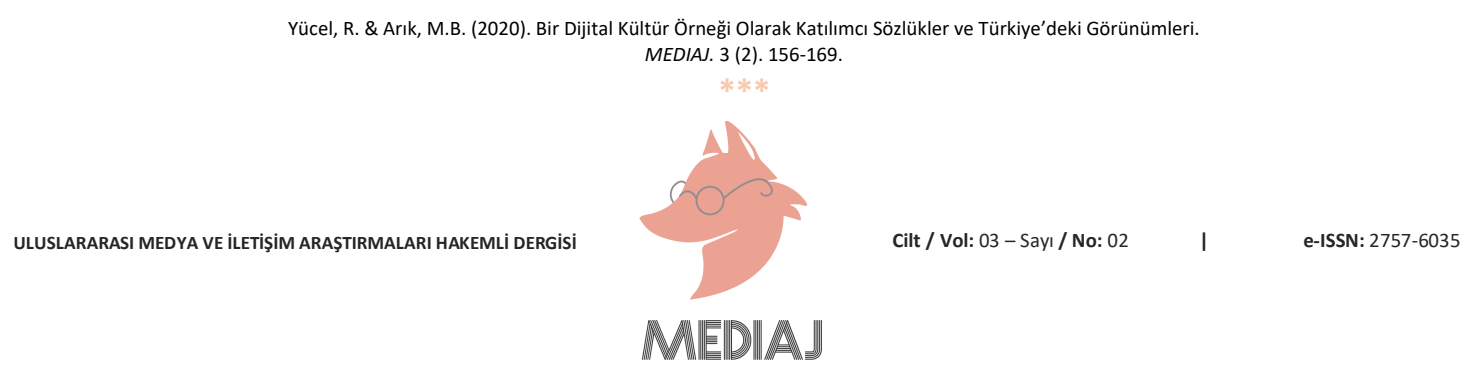

içerik biçimlerinin kesilip parçalanıp yeniden üretilmesi kolaylaşmış ve yaygınlaşmıştır. Dijital katılımcı sözlüklerde kullanıcılar kendi görsel içeriklerini hazırlayabilmekte, var olanları dönüştürebilmekte veya kopyalayarak yeniden dolaşıma sokabilmektedir (Ashton, 2015, s. 103). Zaman içerisinde, dijital sözlüklerde başlayan ve tüm internet ortamına yayılan "caps" yapma alışkanlığı internet kullanıcılarının zaman içerisinde geldikleri beceri düzeyini göstermesi açısından önemli bir örnektir. Dijital sözlüklerde gündelik hayat, politik gelişmeler, kültür ve spor olayları gibi pek çok konuda başlıklar açılmakta ve açılan başlıklara sözlüklere kayıtlı yazarlar tarafından girdiler yapılmaktadır. Girişlerde genellikle kişisel kanaatler, izlenimler yansıtılmakta, tanımlamalar yapılmakta, deneyimler, yaklaşımlar, beğeniler ve eleştiriler dile getirilmektedir. Yazarlar başlıkla ilgili konuda örnekler vermekte; fikirlere, kitaplara veya kişilere referans gösterebilmektedir.

Dijitalleşme küresel ve sanal bir cemaat oluşturmuştur. Geleneksel kodlarla anlaşılamayan, fiziksel sınırları aşmış, yerel cemaatlerin dışında yaşayan bireylerin kendilerinin inşa ettikleri kimliklerle bir araya gelerek meydana getirdikleri topluluktur. Kullanıcılar kendi seçtikleri isimlerle, profillerle bu mecralarda gerçeklikten farklı biçimlerde yaşamaktadır. Öte yandan internet benzer kaygılar ve heyecanlar taşıyan, daha küresel değerlerle donatılmış cemaatleri de oluşturmaktadır. Dünyanın dört bir yanından insanlar pek çok ortak nokta üzerinde görüş oluşturmakta, fikirlerini sunmaktadır. Küresel iklim olayları, salgınlar, politik olaylar, doğal afetler ve sportif müsabakalar bu konuların başlıcalarıdır. Ayrıca bugün, dünya en başta ekonomik olarak hiç olmadığı kadar birbirine entegre olmuş vaziyettedir. Geleneksel ve ekonomik olarak bağımlı haber mecralarından erişemeyecekleri bilgilere internet üzerinden ulaşabilmektedir. Dijital katılımcı sözlükler bu kullanıcı profillerinin yer aldığı ve bilginin serbestçe dolaştığı alanların başında gelmektedir. Küresel katılımcı ağlardan yerel ağlara doğru bilgiler kolayca akabilmektedir. Pek çok kullanıcı hem dijital sözlüklerde hem de Reddit gibi global katılımcı mecralarda yer almakta, bilgilerin mecralar arasında geçişini sağlamaktadır. Geleneksel mecralarda haberleşmeye vakit bulamayan olaylar bu hızlı yayılma sayesinde insanlar tarafından erişilmektedir.

Görüntüyü kaydedebilme, bağlantı sağlayabilme ve görüntüyü işleyebilme gibi yayıncılık gereklerinin aynı cihazlar üzerinde toplanması, yani iletişimin yakınsaması, dijitalleşmenin en önemli unsurlarından birisi olmuştur. Hayatın her anında ve alanında içeriğe dönüşme ve internet ortamında ilgi toplama olasılığı olaylar toplanıp dolaşıma sokulduğu gibi bu aktüel içeriklerin topladığı yorumlar ve beğeniler dijital iletişimin yeni biçimleri olarak ortaya çıkmıştır. Bu çerçevede katılımcı sözlüklerde ilgi toplayan içerikler kazandırmak önemli görülmektedir. Diğer yazarların ilgisini çeken başlıklar açmak, yazılar yazmak, bağlantılar paylaşmak yazarın popülaritesini arttırmaktadır. Katılımcı sözlüklerde, zaman içerisinde bu bağlamda öne çıkan yazarlar, yazılar olmuştur. Yazarlar çoğunlukla "nick name" olarak bilinen isimlerle yazmışlar ve daha sonraki zamanlarda yine aynı isimlerle internetin diğer mecralarında yer alırken sözlükler edindikleri bu tanınırlıkları kendilerinin daha kolay biçimde takipçi ve kitle oluşturmalarını sağlamıştır.

Internet ortamının özellikleri çerçevesinde yazı hem nitelik hem nicelik olarak değişim yaşamaktadır. Katılımcı sözlükler bu değişimin en iyi görüldüğü yerlerden birisi olarak karşımıza çıkmaktadır. Basılı metinler yazar ya da yayıncı tarafından sahiplenilen ve telif hakları yasalarla 


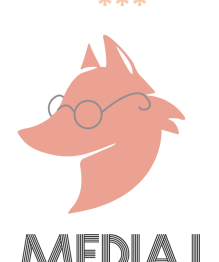

belirlenmiş metinlerdir. Ancak internette hem kullanıcılar hem de metinler anonimleşmiştir. Internet alışılmış olan çizgisel, neden sonuç ilişkisi içerisinde yapılandırılan metinleri uç uca eklenen, bitmeyen bir okumayı gerektiren, kopuk ve bağlamsız bir biçimde yeniden sunmaktadır. Özellikle bağlantıların internet ortamındaki diğer sayfalara ve içeriklere yönlendirmesi okuma ve öğrenme deneyimini yeniden inşa eden bir özelliktir. Bununla birlikte aynı metni birden fazla yazarın farklı zamanlarda bir araya gelerek ürettiği yazılar da internet ortamında mevcuttur. Özellikle internette yazılan katılımcı öykü ve romanlar bu tür yazınlara örnek olarak verilebilir ve bu tür yazınlara "ağ yazını" denmektedir. Dijital sözlükler de bu ağ yazınlarına örnek oluşturmaktadır. Bu haliyle internette özellikle metin ağılıklı içerikler oluşumlarından tüketimlerine kadar postmodern nitelikler yansıtmaktadır.

Dijital iletişim çağında yazınsallığın süreksiz nitelik taşıması eskinin kurulmuş, evvelce belirlenmiş, sürprizlere kapalı ve daha başından sonucu belli yapısına bir karşı çıkıştır. Dijital iletişim çağında ortaya çıkan yazınsallık, klasik yazınsal ve felsefi ölçütlerin süreksizlik ve biçimsel kusursuzluk üzerine belirlediği estetik normları değiştirmektedir. Metnin tümlüğü ve parçalarının birbirine benzemesi durumu dönüşen yazınsallıkta önemini kaybetmektedir. Süreksizlik klasik sanat, felsefe ve yazınsal anlayışı ortadan kaldırmaya dönük bir eylemdir ve bütünlük sunan bilgiye itiraz ederken çözülüp parçalanmayı ivmelendiren bir etkide bulunur. Bütünlük ve anlamda tutarlıık aranması olumlanmaktadır. Dijital iletişim çağında baskın olan yazınsallık merkezsizdir ve giriş, gelişme sonuç doğrultusunda işlemez. Belirli bir yönelim ve doğrultusu olmayan anarşist bir ruha sahiptir (Aktulum, 2008, s. 3).

Bilgisayar teknolojisi bilgi toplumu kavramını insanlığın gündemine getirmiştir. İnternet ortamı ise her haliyle büyük bir bilgilenme mecrasıdır ve dijital katılımcı sözlükler de bu ortamın en tipik örneklerinden birisidir. Ancak bilgi kelimesi bugün çok soyut bir nitelik kazanmıştır. Pek çok farklı türden içerik "bilgi" olarak değerlendirilmektedir. Özellikle Batı literatüründe üç farklı kavram "news, information, knowledge" Türkçe'de "bilgi" kelimesinin ifade ettiği anlamı karşılamaktadır. News haber, information kullanılabilir bilgi, knowledge deneyimlenmiş ve kişiselleştirilmiş bilgi olarak değerlendirilmektedir. Bunların yanında ise wisdom kelimesi de ayrıca bilgelik olarak kullanılmaktadır. Dijital sözlüklerde yer alan bilgiler news ve information kategorisinde değerlendirilebilecek bilgilerdir. Yazarların günlük deneyimlerinden ve anlık ruh hallerinden yansıyan ifadelerin içeriğe dönüşerek kamusal nitelik kazandığı görülmektedir. Bu mecralarda yer alan görüş, fikir ve kanaatlerin diğer okuyucular tarafından kullanıma hazır bilgiler olarak değerlendirilmesi yanıltıcıdır. Öte yandan pek çok görüşün aynı mecraya yansıması "wisdom of crowded" olarak değerlendirilmektedir (Galton, 1907). Aynı olay hakkında yeteri kadar görüş, kanaat ve ifade toplandığında, bu görüş, ifade ve kanaatlerin ortalamasının doğruya ya da doğruya yakın bir sonuca işaret edeceğini söyleyen ve Türkçe'ye "kalabalıkların bilgeliği" olarak çevrilebilecek "wisdom of crowded" teorisine göre sözlüklerin katılımcılı̆ını bir bütün olarak değerlendirmek gerekmektedir. Böylelikle dijital sözlüklerden faydalanmak için gerekli olan beceri yeni bir tür medya okuryazarlığı olarak görünmektedir. Kullanılabilir bilgiyle kişisel yargıları ayırt edebilen, bütünü ve parçaları ayrı ayrı değerlendirebilen, kaynakların nitelikleri ayırt edebilen bir okuma türünün gerekliliği gözlenmektedir.

Dijital ortamlarda üretilen içerikler sadece bir fikir ve ifade hürriyeti kapsamında sarf edilen sözler olmaktan ziyade diğer kullanıcıların ve okuyucuların takdirine, onayına, beğenisine 
sunulan yaşam tarzlarının, zevklerin, eğitim ve bilgi kapasitelerinin, bilişsel becerilerin dışa vurulduğu, karnavala katılan diğerlerinin bir biçimde not verdiği üretimlerdir. Bu çerçevede, dijital katılımcı sözlüklerdeki içerikleri beğeni ve takipçi toplamak üzere hazırlandıklarını da göz önünde bulundurmak gerekmektedir. Sözlüklerde içerikleri beğenme, yazarları takip özellikleri mevcuttur. Popüler ve gündemde olan başlıklarda girdiler yaparak görünürlüğü arttırmak, reyting oluşturmak mümkündür. Polemik alanlarında var olmak, belki diğerlerinden daha usta polemikçi olmak, konuya derinlemesine bakmaktan, farklı bakış açıları üretmekten daha değerli olabilmektedir. Bu haliyle sözlüklerde ifadeler belirli nesnel koşullarda değerlendirilmiş bilgiler olmaktan ziyade ortamda gerçekleşen iletişimin doğasına göre tasarlanmış, popüler düzey hedeflenmiştir. Bu ortalama düzeye dönük söz söyleme anlayışı çoğu zaman nefret söylemi, ayrımcılık, küfür ve hakaret üretebilmektedir. Çok fazla sayıda yazar ve içeriğin her gün aynı mecrada yarattığı trafiği dijital sözlüklerdeki editör ve moderatörlerin yönetmesi mümkün gözükmemektedir. Bu durumda yazarların veya kullanıcıların sorumluluklarının farkında olması gerekmektedir. Diyalog ortamının ve sözlüklerde kullanılan dilin toksikleşmesi, toplulukların ortak iyiliğine zarar vermektedir. Bu açıdan bakıldığında sadece okurların değil, yazarların da yeni bir okuryazarlık anlayışına ve etik kodları geliştirmelerine intiyaç olduğu ortadadır. Beğeni ve takdir kaygısının içerikler üzerinde yarattığı baskının dil ve ifadelerdeki olumsuz yansımalarının çözümü daha kuşatıcı ve güçlü ahlak anlayışının herkes tarafından benimsenmesinde, ortak sorumlulukların farkındalığında yatmaktadır.

\section{Türkiye'de Katılımcı Sözlüklerin Kısa Tarihi}

Türkiye'deki ilk dijital katılımcı sözlük Sedat Kaplanoğlu'nun 15 Şubat 1999 tarihinde Dougles Adams'ın Otostopçunun Galaksi Rehberi isimli kitabından ilham alarak hayata geçirdiği ve diğer katılımcı sözlüklere de örnek olan Ekşi Sözlük'tür. Ekşi Sözlük'ün sloganı “Kutsal Bilgi Kaynağı”dır. Ekşi Sözlük'te yazar alımları belli dönemlerde yapılmakta ve her bir dönem alınan yazarlar ayrı jenerasyonlar olarak değerlendirilmiş, 2010 yılı itibariyle jenerasyon farklılıkları ortadan kaldırılmıştır. Ekşi Sözlük; sözcük, terim, kavram ve kişilere ilişkin bilgi, deneyim, gözlem, espri, yorum, anket, link ve kaynak içeren interaktif bir mecra, veri tabanıdır. Ekşi sözlük daha teknik bir ifadeyle, bünyesinde barındırdığı yazarların görüşlerini içerik olarak sunan, collaboravie hypertext dictionary niteliğinde bir yapıdır.

Yazarlar belirli bir fikir ya da konseptle sınırlamamışlar, tamamen özgür iradeleriyle yazmaktadırlar. Sözlükler bir tür meclis, konuşma tartışma platformu gibi de görülebilirler. Söyleyecek sözü olan, tespiti olan, rahatsızlık duyan, daha farklı olanı talep eden veya öneren, yaratıcı bir bakış açısını sunmak isteyen gençlerin buluştuğu bir söz söyleme meclisidir. Yorumu yapan, bakış açısını sunan kimse kendi kimliği, yetişme tarzı, eğitimi düzeyi ile ilgili de bilgi sunarak kamusal alanda var olurken, yorum yaptığı başlıkta ifade edilen durum ya da olaya nasıl baktığını kendi penceresinden sunarak anlam zenginliği oluşturmaktadır. Alternatif tanımlamalar, yorumlamalar, yaklaşımlar dijital iletişim ortamlarının postmodern kültüre yaptığı muazzam bir katkıdır (Gürel ve Yakın, 2007, s. 210).

Ekşi Sözlük yazarın özgürlük alanları kısıtlamaması ve çoğu zaman girilen içeriklerin denetimlerinin yeterli olamaması nedeniyle pek çok defa hukuki sorunlarla karşılaşmıs ve bu sebeplerle Ekşi Sözlüğün erişimi pek çok defa durdurulmuştur. 2006 yılında Türk Telekom ile, 2007 yılında Türkiye'de Adnan Hoca grubu olarak bilinen kült hareket ile, 2010 yılında gazeteci 


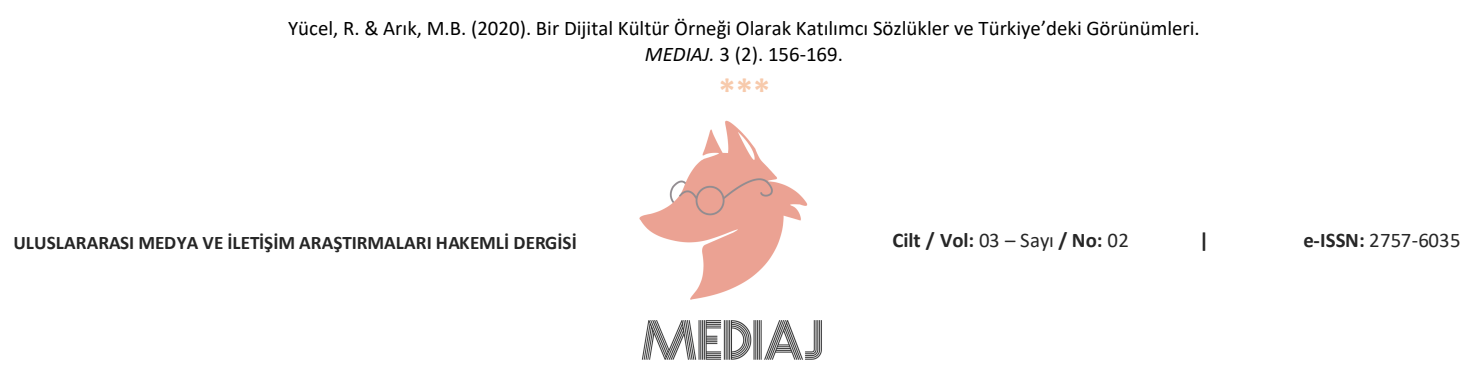

Fatih Altaylı ile yaşanan hukuki sorunlardan dolayı sözlük bazı yaptırımlarla karşı karşıya kalmıştır. 2011 yılında Telekomünikasyon İletişim Başkanlığı sözlüğün sunucusundan sözlüğe erişimin durdurulmasını istemiş, yine aynı yıl 35 sözlük yazarı manevi değerlere hakaret ettikleri iddiasıyla hâkim karşısına çıkarılmıştır. Ekşi Sözlük Türkiye'de her zaman en çok ziyaret edilen sitelerden birisi olması nedeniyle her en fazla göz önünde olan platformlardan birisi olmuştur. Türkiye'nin yaşadığı siyasi iklimden ve olaylardan sıklıkla etkilenmiş, baskı erişim engellerine maruz kalmıştır. Ekşi Sözlük bünyesinde yazarlık yaparak sesini duyuran ve tanınan pek çok yazar zamanla başka mecralarda da seslerini duyurmaya, yazarlık yapmaya ve internet fenomenliği yapmaya başlamışlardır. Ekşi Sözlük yazarlık alımlarını sınırlı tuttuğu için pek çok klon sözlük türemiş̧ir. 2008 yılına gelindiğinde klon sözlüklerin toplamı 88 adete ulaşmıştır.

Bu klon sözlüklerin en bilineni ve bir diğer dijital katılımcı sözlük 2009 yılında Serkan İnci ve İsmail Alpen tarafından kurulan İnci Sözlük'tür. İnci Sözlük gerek müstehcen dili gerekse ana akım medyada yer alan bazı program ve sunucuları "trollemeleri" dolayısıyla bilinirlik kazanmıştır. İnci Sözlügün internet dünyasına önemli kazanımlarından birisi de "caps" kültürü olmuştur. Ekran görüntüsünün fotoğraf formatında kaydedildiği ve mizahi bir dille hazırlanan kısa bir metinle birleştirilerek üretildiği "caps”ler, halen internet ortamında kullanılmaktadır. İnci Sözlük de tıpkı Ekşi Sözlük gibi ifade özgürlüğünün sınırları ihlal edildiği gerekçesiyle sıklıkla mahkeme süreçlerinden geçmektedir. İnci Sözlük 2011 yılında yapılan genel seçimlerde, dönemin internette en çok ilgi gören videolarından birisin kahramanı olan Ahmet Yılmaz'ı milletvekili adayı göstermiştir. İnci Sözlük Başakşehir Futbol takımının taraftar grubu olan Boz Baykuşlar'ı da bünyesinden çıkarmıştır. İnci Sözlük Ekşi Sözlük'e oranla daha müstehcen bir dil kullanıımasına müsaade etmiş, içeriklerinde yer alan bilgilerin doğruluğundan sorumlu olmadıklarını ifade etmiştir. (Üngüren, 2019, s. 2888).

Dijital etkileşimli sözlüklerin önemli örneklerinden birisi de üniversite sözlükleridir. Bu alandan bilinen sözlükler ITÜ Sözlük ve Uludağ Sözlüktür. ITÜ Sözlük 2004 yılında İstanbul Teknik Üniversitesi öğrencilerine hizmet vermesi amacıyla Çağatay Gürtürk tarafından kurulmuş ve kuruluşun birkaç ay sonra daha geniş bir katılıma açılarak sözlüğün kitlesi ve etkinliği genişletilmiştir. ITÜ Sözlük en başından beri sözlük dışında bir sosyal medya özellikleri göstermiş, bu çerçevede 2007 yılında üyelerinin kullanımına dönük olarak "ajanda, not defteri, duyurular" gibi uygulamaları hazırlayıp sunmuşlardır. 2008 yılında dijital katılımcı sözlükler içerisinde ilk defa yazılan metinlere görsel ve video desteği vermeye başlamıştır. iTü sözlük 2015 yılından itibaren sözlük yapısını terk etmiş ve global hedeflerle "Instela" isimli bir topluluğa evirilmiştir. Bir diğer üniversite sözlüğü olan Uludağ Sözlük 2005 yılında İsmail Alpen tarafın kurulmuştur. Halen hayatına devam etmekte olan Uludağ Sözlük'ün yüzde 50'si 2019 Eylül ayında bir iş adamı tarafından satın alınmıştır.

IHL Sözlük de önemli katılımcı sözlük örneklerinden birisidir. Nisan 2009'da kurulmuş, yayın hayatına 2012 yılında ara vermiş, 2015 yılında tekrar geri dönmüşse de 2016 yılında Dünya Sözlük çatısı altına girmiştir. Yayın hayatına başladıktan kısa süre sonra en sık ziyaret edilen üçüncü katılımcı sözlük konumuna gelmesine rağmen tutunamamıştır. Kendilerini küfür, müstehcen ve argo ifadelerden uzak bir alanda konumlandırmayı hedefleseler de yayıncılık ömürleri uzun olamamıştır. 


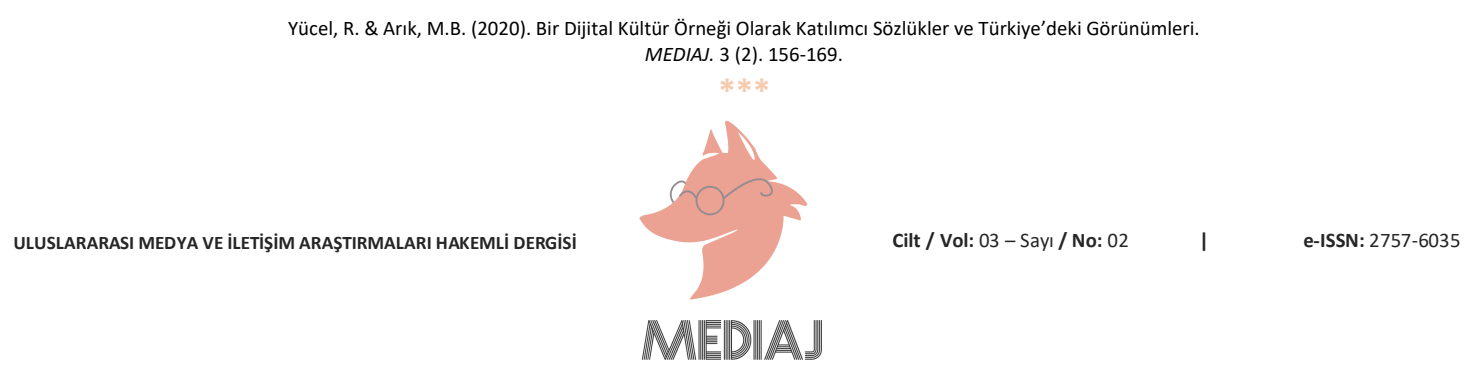

Tematik katılımcı sözlükler belirli dönemlerde hayata geçirilmiş ancak aktif biçimde kullanılmamıştır. Sportif Sözlük, Siyaset Sözlük gibi sözlükler gelişememiş ve kapanmıştır. Sinema Sözlük halen erişime açıksa da içerik güncellemeleri gözlenememektedir.

Türkiye'de dijital katılımcı sözlüklerin tarihçesini özetlemek gerekirse 1999 'da Ekşi Sözlük ile başlayan akım pek çok farklı sözlüğün katılımıyla zaman içerisinde genişlemiştir. Ekşi Sözlük özellikle gençler arasında çok popüler olmuş, yazar olmak ve dijital mecralarda aktif olmak isteyen gençler Ekşi Sözlüğün yeteri kadar yazar kontenjanı açmaması sebebiyle farklı mecralara yönelmesine, sözlük klonlarının ortaya çıkmasına sebep olmuştur. Bu girişimlerin bugün pek azı hayatlarına devam edebilmektedir. Ekşi Sözlük yarattığı kültürün halen taşıyıcısı konumundadır ve halen en sık ziyaret edilen sitelerden birisidir. Özellikle tematik siteler bağlamında bakılacak olursa yeterli ziyaretçi oluşturamadıkları görülmektedir. Ekşi Sözlük özgürlükçü ifade ortamıyla hem okuyucuları hem de yazarları bünyesinde toplamış, her zaman güncel, renkli ve dinamik bir ortam olmayı sürdürmüştür.

\section{Dijital Katılımcı Sözlüklere Yönelik Eleştiriler}

Dijital iletişim teknolojilerinin insan hayatına kazandırdığı en önemli değer herkesin sesini duyurabileceği bir ortam oluşturmasıdır. Geleneksel iletişim araçlarının tek yönlülükleri ve sermaye ilişkileri içerisinde oluşan kurumsallıkları her kesimin sesinin kamusal alanda duyulmasına imkân sağlayamamıştır. Internet ağı ve dijital iletişim araçları herkesi bir iletişim birimine, ağ üzerinde bir düğüm konumuna getirmiştir. Bu yeniliğin olumlu yönde getirileri olduğu kadar olumsuz birtakım sonuçları da gözlenmektedir. Dijital katılımcı sözlükler çerçevesinde değerlendirme yapılacak olursa en sık rastlanan olumsuzluk nefret söyleminin çok çabuk ortaya çıkıp yayılabilmesidir. Nefret söylemi çok eski bir sorun olmakla birlikte, bilgisayar kültürü içerisinde doğan ve onun nimetlerinin en büyük kullanıcısı olan gençler arasında sanal ortamda da üretildiği çeşitliği araştırmalarda ortaya konmaktadır (Alp, 2016; Dondurucu, 2018; Öztekin, 2015; Sine ve Özsoy, 2017). Yaşanan politik ve sosyal olaylarla bağlantılı olarak sözlük yazarları tarafından gerek inanç temelinde gerek etnik farklılıklar boyutunda ayrımcılıklara, nefret söylemlerine rastlanmaktadır. Türkiye özellikle 2010 ve 2020 yılları arasında pek çok sebeple sandık başına gitmiş ve bu anlamda seçim ve siyasal propaganda süreçleri yaşamıştır. Bu süreçler kutuplaşma ve ayrımcılık açısından pek çok örnek barındırmaktadır. Bu örneklerin görünür olduğu sanal mecralar olarak katılımcı sözlükler yıkıcı ve ayrımcı ifadelerle doludur. "Katılımcılık" pek çok farklı fikir ve görüşün bir araya gelerek zengin tartışma ortamlarının oluşmasına katkı sağladığı gibi, duygusal tepkilerin kontrolden çıkarak kitleselleşmesine ve toplumlar için sakıncalı durumlar doğurduğu da görülmektedir. Dijitalleşmenin sunduğu imkanların ifade özgürlüğünün ötesine taşan ve nefret söylemi (Yardım ve Dalkılıç, 2018) boyutuna varan kötüye kullanımı, ifade özgürlüğü konusunun yeniden ele alınmasına, özellikle otoriterleşmeye eğilimli ortamlarda bir takım sınırlamalara sebep olarak gösterilmesine neden olmaktadır. Bu anlamda ifade özgürlüğünün bireyler adına bir sorumluluk olarak belirdiği ve kullanıcılar tarafından istismar edilmesi durumunda, hassas diyalog ortamlarında sorumsuz davranışların gerçek tahribatlar yarattığı görülmektedir (Uzunoğlu, 2015).

Dijital katılımcı sözlükler gerçek ile gerçek olmayanın ayırt edilmesinin oldukça güç olduğu platformlardır. Kullanıcıların kişisel kanaatleri ve deneyimleri ana akım medyanın yayınladığı haberlerden ve resmî kurumların açıklamalarından farklı bir boyutta değerlendirilmekte ve bu 


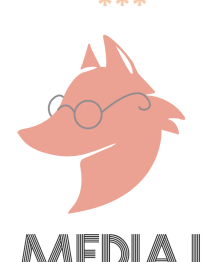

halleriyle de oldukça kıymet arz etmektedir. Kamusal boyutu olan bir olaya yakından tanık olan bir yazarın deneyimlerini paylaşması, herhangi bir filtre kullanmaksızın aktarılan bilgi olarak önemlidir. Ayrıca pek çok değerli yorum ve deneyimin aynı alanda bulunması okuyanlar için derinlemesine bilgilenme için imkân da sağlayabilmektedir. Ancak bazı durumlarda gerçek olmayan içerikler de gerçekmiş gibi sunulmaktadır. Bu noktalar gerçek ile gerçek olmayanın sınııının belirsizleștiği ve insanların yanlış yorumlamalara sapabildiği yerlerdir. Özellikle Türkiye gibi kamusal tartışma kültürünün ve vatandaşlık bilincinin henüz gelişmediği bir yerde, küçük farklılıklardan başlayan tartışmaların büyüyerek herkesin kendi kamplarına çekilip nefret söylemlerinin kullanılmaya başlandığı gözlenmektedir. Böylesi tartışma ortamlarında yalan ve yanlış bilgilerin yıkııılığı daha da katlanmaktadır. Kamusal tartışmaları etkilemek isteyen çevrelerin katılımcı sözlüklerde etkinlik göstermesi ve kendi çıkarlarına hizmet eden içeriklerle kamuoyunu yönlendirmesi olasıdır. Nitekim pek çok siyasi oluşum ve grup genelde sosyal medyada, özelde de dijital katııımcı sözlüklerde gerek tanıdıkları sözlük yazarları gerekse halkla ilişkiler ajansları vasıtasıyla bu alanlardan fayda elde etmek adına etkinlikte bulunmaktadır. Bu çerçevede dijital katılımcı sözlüklerde yer alan bilgilerin değerlendirilmesinin okuyucu tarafından dikkatle yapılması gerekliliği ortadadır.

Dijital katılımcı sözlüklerde yer alan argo, küfürlü ifadeler ve hakaretler özellikle küçük yaştaki kullanııılar için risk oluşturmaktadır. Ebeveyn kontrollerinin zayıf olduğu veya olmadığı ailelerde henüz zihinsel ve fiziksel olgunluk kazanmamış kullanıcılar için pek çok risk faktörü mevcuttur. Bu konuda teknoloji şirketler, bağlantı sağlayıcılar ve eğitimciler özellikle son yıllarda oldukça çaba sarf etmektedir. Ancak dijital katılımcı sözlükler anlamlı ve değerli bilgilerle zararlı içeriklerin bir arada olabildiği ortamlar olarak bilinmektedir. Bir şekilde bağlantılarla yolu sözlüklere çıkan çocuklar, otoriteler tarafından filtre edilmediğinde, olumsuzluk yaratacak içeriklerle karşılaşabilmektedir. Ekşi Sözlük (Üngüren, 2019, s. 2888) başta olmak üzere katılımcı sözlükler gerek nefret söylemleri gerekse olumsuz örnek olabilecek diğer içerikler sözlük yöneticileri tarafından silinmektedir ancak yoğun katılımın olduğu zamanlarda bütün içerikleri kontrol edebilmek ve gerekli sınırlamaları koyabilmek güçleşmektedir.

Sözlükler uzmanların içerik oluşturduğu alanlar değillerdir. Kamusal dolaşıma sokulmakta olan bilgilerin nesnelliği, doğruluğu ve tarafsızlığı, tartıştıkları konularda kaygı taşımak zorunda olmayan, çoğunlukla eğlenmek ve söyleyecek sözlerini sarf etmek amacıyla katılan kimselerin olduğu platformlardır. Yazarlık esasen söylenen sözün sorumluluğunu taşıma mesleğidir. Ancak takma isimler veya kullanıcı isimleriyle bu sorumluktan kaçma imkânı doğmaktadır. Bu kaçış alanı yazar sorumluluğunun ve güvenilir bilginin zayıflamasını beraberinde getirmektedir. Sözlükler zengin olmakla beraber güvenilirlikleri düşük mecralardır. Uzmanlar kariyerlerini belli alanlarda birikim edinmeye adamış kimselerdir. Sundukları görüşler ve bilgiler belli bir düzen ve referans sistemine dahil olmakla birlikte hesap verebilirlikleri de yüksek kimselerdir. Ancak herkesin yazar olup bilgi sunduğu ortamlarda gerçek uzmanlıkların da değeri azalmakta ve bütün içerik belli bir ortalamada buluşmaktadır. Bilginin niteliğinin takdir edilmesi yine okuyucuların sorumluluğundadır ve yine medya okuryazarlığına ihtiyaç vardır.

\section{SONUÇ}

Mesaj iletişim aracının yapısına göre yapılanmaktadır. Bağlantısı ve teknik altyapısı olan herkesin paydaşı olabildiği bir iletişim ortamında çok seslilik oluşmaktadır. Bu çok seslilik insanların daha 


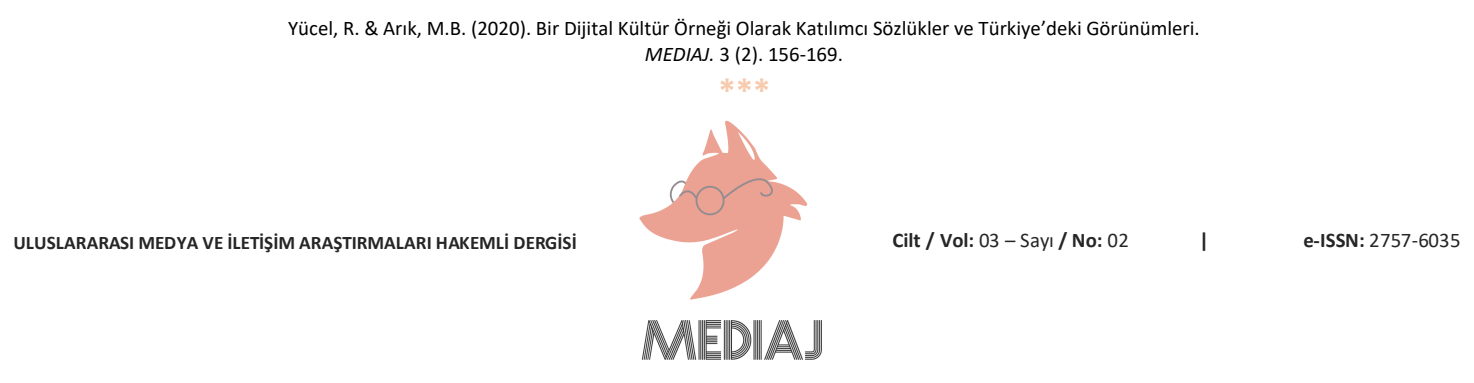

eşit bir dünyayı paylaşması için önemlidir. Öte yandan internet insanlara, bilgiye ulaşmak bakımından daha evvel görülmemiş imkanlar sunmaktadır. Herkesin bir miktar bilgi sahibi olabildiği ve sözünü duyurmak istediği bir iletişim evreni ortaya çıkmaktadır. Bu evrende sözler matbaa evrenine oranla daha duygusal ve kişisel deneyimin merkeze geçtiği ifadeleri oluşturmaktadır. Diğer yandan yazarlığın ustalığı ve uzmanlığın birikimi flulaşmaktadır (Ericsson, 2006).

Nasıl ki basılı araçlar yazarlık ve otorite kavramının ortaya çıkmasına zemin hazırlamıştır (Burke, 2001, 23), benzer şekilde dijital ortam aynı kavramları aşındırmaktadır. Herkes yazar ve otorite olabilmekte, kendi sesini duyurmak için meşgul olurken dinlemeye daha çok zaman ayırmaktadır. Kaliteli ve faydalı bilgiler, gerçeğin insanı aydınlatacak yüzü, en başta yankı odaları olmak üzere internetin gürültüsünde kaybolup gitmektedir. Yazarın sözün sahibi olduğu, anlatının bütünlüklü ve neden sonuç ilişkisi içinde inşa edildiği modern matbaa evreni dijital ortamda çok yazarlı anonim ortaklıklarla parçalanmaktadır.

Postmodern kültürde parçalılık, dağınıklık artarken belirli bir merkeze duyulan ihtiyaç ve yekparelik beklentisi azalmaktadır. Geleneksel iletişim araçları tarafından şekillendirilen ve onları şekillendiren, her bir hücresinde evrensel ve bütüncül bir dünya tasavvurunu işleyen moderniteye; dijital iletişim araçlarının biçimlendirdiği postmodernizm, bütünden ayrılarak farklılık yaratan, "süreksiz" ve "parçalı" olan ile meydan okumaktadır. Parçalılık, bütünden ayrılarak farklılık sunmak, süreksizlikliğin dildeki ve dolayısıyla yazıdaki sonucu, modern yazı alışkanlıklarının farklılaşması olmuştur. Dijital sözlüklerde var olan katılımcılık beraberinde parçalılığı ve çeşitliliği getirmektedir. Gerçekleşen dilsel çeşitlilik imkanında ayrışık olma durumu dijital iletişim ortamının yeni normali olarak belirmektedir. Yazarın bir bütün olarak metni oluşturduğu geleneksel biçim kaybolmaktadır. Konu hakkında fikri ve söyleyecek sözü olan yazar, elindeki iletişim imkanlarını kullanarak yazıma katılmakta, karnavalın bir parçası olmaktadır.

Katılımcı sözlükler dijitalleşmenin getirdiği imkanlardan sonuna kadar faydalanan platformlardır. Dijital sözlükler gündelik hayata, politikaya, kültür, spor olaylarına dair başlıklar açılan ve açılan başlıklara yazar tarafından girişlerin yapıldığı sanal ortamlardır. Girişlerde tanımlamalar yapılmakta; kişisel tecrübeler, yaklaşımlar, beğeniler ve eleştiriler yer almaktadır. Yazarlar başlıkla ilgili konuda örnekler vermekte; fikirlere, kitaplara veya kişilere atıfta bulunulabilmektedir. Sözlüğün kendisine has bir jargonu vardır ve genellikle dijital çağın içinde doğup büyümüş gençler tarafından kullanıldığından bu jargonu kendisine has özellikler barındırmaktadır.

Türkiye'de 1999 yılında Ekşi Sözlük'le başlayan katılımcı sözcüklerin tarihçesi, ondan sonra onlarca sözlük yayın hayatına başlasa da Ekşi Sözlük'ün yörüngesinde devam etmiştir. Alternatif ve farklı sözlükler de bu alana ilişkin teşebbüslerde bulunsalar da hem etkinlikleri hem de süreklilikleri çok tatminkâr olmamıştır. Halihazırda bu alanda ciddi bir okur sıkıntısı olduğu açıktır. Öte yandan özellikle sosyal medya platformlarının doğuşu ile kullanıcı ilgisinin başka mecralara döndüğü gözlenmektedir. Facebook ve Twitter ile başlayan dönem Ekşi ve İnci Sözlük haricinde kalan diğer katılımcı sözlük girişimlerinin etkilerinin beklenen düzeye erişemeden kapanmalarına neden olmuştur. Özellikle Ekşi Sözlük bünyesinde insanların ilgisi çeken girişler yapan yazarlar, geliştirdikleri bu becerileri sayesinde zaman içerisinde diğer sosyal medya platformlarında takipçi kazanarak etkinlik göstermişlerdir. Sözlük yazarları daha etkileşimli ve 


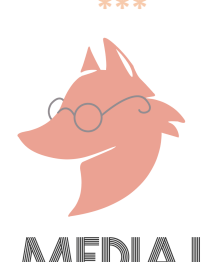

daha çok kimsenin daha kolay eriştiği sosyal ağlara yönelmesi bütün dijital sözlük platformları açısından güç kaybı olmuştur. Ancak Ekşi Sözlük her zaman belirli bir okur kitlesini muhafaza etmeyi başarmış, ortaya çıkan sosyal medya platformlarını faydalanacağı biçimde kullanmanın yollarını bulmuştur. Ekşi Sözlük her an artan içeriğinden öne çıkanları, insanların ilgi gösterdiklerini düzenleyerek "ekşi şeyler" başlı̆ı̆ altında vermeye devam etmektedir. Ekşi Sözlük ayrıca Pena isimli kendi Youtube kanallarında orijinal içerikler, programlar üretmektedir. Bu programlarda kendi yazarlarından gelen sorular katılan konuklara canlı yayınlarda okutularak cevaplar alınmaktadır. Siyasetçiler, yazarlar, oyuncular ve daha pek çok alandan gündemde olan kimseler bu programlarda yer almaktadır. Ekşi Sözlük sosyal medya hesaplarından kendi etkinliklerini ve içeriklerini paylaşarak okuyucuların ilgilerini çekmeye devam etmektedir. Türkiye'de yirmi yılı aşkın biçimde hayatına devam eden katılımcı sözlükler ve özelde Ekşi Sözlük hem içerikleri hem de yarattığı kültür bakımından toplumsal bir fenomene dönüşmüş durumdadır.

Son olarak katılımcı sözlüklere getirilen eleştirilere baktığımızda, burada da dijitalleşmenin getirdiği teknolojik yeniliklerin sonucunda ortaya çıkan kullanım alanlarının tam olarak anlaşılamadığı ve kullanım kültürlerinin oluşmadığı gözlenmektedir. Bilginin ile insanlar arasında sınırları kaldıran dijitalleşme bu anlamda bazı sorunları da beraberinde getirmiştir. Denetlemenin yetersiz olması ve kullanıcıların ifade özgürlüğü kavramını bilmemelerinden dolayı sıklıkla nefret söylemine rastlanmaktadır. Ayrıca, dijital ortamda bazı şiddet olaylarının övüldüğü ve taraftar topladığı da gözlenmektedir. İfade özgürlüğüne ve bilginin yayılmasına açılan alanın sakıncalı kullanımla tartışmalı hale geldiği görülmektedir. Platformlar ve sözlükler yine kullanıcıların desteğiyle kötüye kullanımı azaltmaya gayret etmektedir. Geride kalan dijitalleşme deneyimine bakılarak söylenebilir ki kullanıcıların okuryazarlık becerilerinin gelişmesi en doğru çözümdür. Bir takım yasal sınırlamalar aynı zamanda ifade özgürlüğünü ve bilginin dolaşımını da sınırlamaktadır. Bu tür durumlarda dijitalleşmenin getirilerinin erozyona uğradığı ve yine oluşan kaybın bedelinin kullanıcıların ödediği açıktır. Gerek demokrasinin işleyişi gerekse toplumun kesimleri arasındaki bilgi uçurumunun kapanması adına sorumlu kullanıcı ve okuryazar kültürünün ve daha genelde bu kültürün temeli olacak ahlak kodlarının geliştirilmesi hayati konumdadır.

\section{KAYNAKÇA}

Aktulum, K. (2008). Parçalılık/Süreksizlik/Kopukluk. Süleyman Demirel Üniversitesi Güzel Sanatlar Fakültesi Hakemli Dergisi, 1(1), 1-14.

Alp, H. (2016). Çingenelere Yönelik Nefret Söyleminin Ekşi Sözlük'te Yeniden Üretilmesi. ilef Dergisi, 3(2), 143-172. https://doi.org/10.24955/ilef.305520

Arık, E. (2018). Dijital Mahremiyet. Literaturk Yayınlar.

Ashton, D. (2015). Producing participatory media: (Crowd) sourcing content in Britain/life in a day. Media International Australia, 154, 101-111. https://doi.org/10.1177/1329878×1515400113 
Aydoğan, D. (2014). Romanda Dijitalleşme: E-Kitap. The Turkish Online Journal of Design, Art and Communication, 4(4), 16-32.

Burke, P. (2001). Biginin Toplumsal Tarihi. Tarih Vakfı Yurt Yayınları, İstanbul.

Castells, M. (2013). Ağ Toplumunun Yükselişi: Enformasyon Çağı: Ekonomi, Toplum ve Kültür (3rd ed.). Bilgi Üniversitesi.

Dondurucu, Z. B. (2018). Yeni Medyada Cinsel Kimlik Temelli Nefret Söylemi: İnci Sözlük Örneği. Gümüşhane Üniversitesi Iletişim Fakültesi Elektronik Dergisi, 2, 1377-1405.

Ericsson, A. K. (2006). The Cambridge Handbook of Expertise and Expert Performance (P. J. Ericsson, Andres; Charness, Neil; Hoffman, Robert. R; Feltovich (ed.)). Cambridge University Press.

Galton, F. (1907). Vox Populi. Nature, 75(1949), 450-451. https://doi.org/10.1038/075450a0

Göker, G. (2015). İletişimin Mcdonaldlaşması: Sosyal Medya Üzerine Bir İnceleme. Journal of Turkish Studies, 10(Volume 10 Issue 2), 389-389. https://doi.org/10.7827/turkishstudies.7641

Gürel, E., \& Yakın, M. (2007). Ekşi Sözlük: Postmodern Elektronik Kültür. Selçuk Illetişim, 4(4), 203-219.

Öztekin, H. (2015). Yeni Medyada Nefret Söylemi: Ekşi Sözlük Örneği. Uluslararası Sosyal Araştırmalar Dergisi, 8(38), 925-936.

Rengin, S., \& Öztürk, S. (2017). Ekşi Sözlük Kullanıcılarının Yeni Medya Kullanım Pratikleri. Route Educational and Social Science Journal, 4(8)(December), 53-65.

Uzunoğlu, S. (2015). Bir postmodern Intiharın Ardından Ekşi Sözlük'te Kanaatlerin Oluşumu ve Grupların Biçimlenme Süreçleri. 2(2), 424-439.

Üngüren, E. (2019). Yeni Medya Illetişim Kanalı Olarak Katılımcı Sözlük Sitelerine Yönelik Bir Değerlendirme. OPUS Uluslararası Toplum Araştırmaları Dergisi. https://doi.org/10.26466/opus.567125

Van Dijk, J. (2018). Ağ Toplumu. Kafka Epsilon Yayıncılık.

Yardım, M., \& Dalkılıç, M. (2018). Nefret Söylemi ve ifade Özgürlüğü Tartışmaları Çerçevesinde İslamofobya: L'Express Dergisi Örneği. Medya ve Din Araştırmaları Dergisi, 1(1), 89-109. http://dergipark.gov.tr/mediad/issue/37949/422078 